\title{
Effects of Sn Content and Aging Conditions on Superelasticity in Biomedical Ti-Mo-Sn Alloys*1
}

\author{
Takashi Maeshima $^{1, * 2}$, Satoshi Ushimaru ${ }^{1, * 2}$, Kiyoshi Yamauchi ${ }^{2}$ and Minoru Nishida ${ }^{3}$ \\ ${ }^{1}$ Graduate School of Science and Technology, Kumamoto University, Kumamoto 860-8555, Japan \\ ${ }^{2}$ Biomedical Engineering Research Organization, Tohoku University, Sendai 980-8579, Japan \\ ${ }^{3}$ Department of Materials Science and Engineering, Kumamoto University, Kumamoto 860-8555, Japan
}

\begin{abstract}
The effects of Sn content and aging conditions on superelasticity in Ti-Mo-Sn alloys were investigated. Martensitic transformation temperature decreased with an increasing of Sn content. A large superelastic strain of 3.0\% was obtained in a solution-treated Ti-5 mol\% Mo$5 \mathrm{~mol} \% \mathrm{Sn}$ alloy in the tensile test. The superelasticity in the Ti-5 mol\% Mo- $5 \mathrm{~mol} \% \mathrm{Sn}$ at room temperature was improved by aging at $873 \mathrm{~K}$ for short periods between 180 and $420 \mathrm{~s}$. A specimen aged at $873 \mathrm{~K}$ for $300 \mathrm{~s}$ exhibited superelasticity with a recovery strain of $3.5 \%$ in the tensile test. A recovery strain of $3.0 \%$ was consistently achieved in cyclic tensile deformations.
\end{abstract}

(Received September 20, 2005; Accepted December 15, 2005; Published March 15, 2006)

Keywords: $\beta$-titanium alloy, titanium-molybdenum-tin, tin content, heat treatment, superelasticity, martensitic transformation, smart biomaterials

\section{Introduction}

Among many shape memory alloys, only Ti-Ni alloys are now widely used and are still being developed as biomaterials such as orthodonitic wire, teeth-root prosthesis, stent in blood vessels, because of their superior shape memory property and superelasticity. However, it has been suspected that pure $\mathrm{Ni}$ is a toxic element and causes Ni-hypersensitivity to the human body. Any suspicion should be eliminated in the biomedical applications. Although clear Ni-hypersensitivity to the human body in $\mathrm{Ti}-\mathrm{Ni}$ alloys has not been reported yet, the development of absolutely safe Ni-free Ti-based shape memory alloys for biomedical applications has been required.

It is well known that quenching from $\beta$ phase leads to the two martensitic transformations from the $\beta$ (disordered bcc) phase to either $\alpha^{\prime}$ martensite (hexagonal) and $\alpha^{\prime \prime}$ martensite (orthorhombic) in $\beta$-type Ti-based alloys. It has been reported that the reverse transformation from the $\alpha^{\prime \prime}$ phase to the $\beta$ phase causes shape recovery to appear. ${ }^{1)}$ Recently the ternary $\beta$-Ti alloy that exhibited the shape memory effect with this transformation was reported by many researchers. $^{2-11)}$

Biomedical shape memory alloys are required to have not only excellent shape memory effect but also biocompatibil$i^{12)}$ and superior corrosion resistance. The Ni-free ternary $\beta$-Ti alloys satisfy the above requirements. The present authors have systematically investigated the shape memory effect of Ti-Mo-X (X = Ag, Sc, Sn) and have confirmed the appearance of the superior shape memory effect. ${ }^{8-10)}$ However, superelasticity with the large recovery strain around human body temperature is necessary to apply the newly developed alloys to biomedical applications. We reported the possibility that superelasticity at body temperature appears at the amount of $\mathrm{Sn}$ contents more than $4 \mathrm{~mol} \%$ in the $\mathrm{Ti}-$ 5 mol\%Mo-Sn alloys. ${ }^{8)}$ In the present study, in order to

\footnotetext{
*1 This Paper was Originally Published in Japanese in J. Jpn. Inst. Met. 69 (2005) 654-658

${ }^{*}$ Graduate Student, Kumamoto University
}

develop Ni-free Ti-based biomedical superelastic alloys, the effects of Sn content and aging conditions on superelasticity in Ti-Mo-Sn alloys were investigated.

\section{Experimental Procedure}

Ti-5 mol\%Mo-(0-6) mol\%Sn ingots were arc melted in an $\mathrm{Ar}$ atmosphere using pure $\mathrm{Ti}$ (99.7 mass\%), pure Mo $(99.95$ mass $\%)$ and pure Sn $(99.9$ mass $\%)$. Hereafter, Ti5 mol\%Mo-X mol\%Sn is abbreviated to Ti5MoXSn. Weight changes after arc melting were negligibly small in the all alloys. The ingots were homogenized at $1373 \mathrm{~K}$ for $86.4 \mathrm{ks}$ in vacuum, followed by hot and cold rolled into plate of about $0.4 \mathrm{~mm}$ in thickness with a final rolling ratio of $95 \%$. Specimens with prescribed shapes were prepared by spark machining from the rolled plates. They were encapsulated in an evacuated quartz tube, solution-treated at $1273 \mathrm{~K}$ for $1.8 \mathrm{ks}$ and quenched into iced water with breaking tube. Some specimens were aged in the temperature range between 623 and $873 \mathrm{~K}$ for various periods after the solution treatment and followed by quenched into iced water.

In order to evaluate the shape memory properties, the convenient bending test was carried out at room temperature. The specimens with a thickness of $0.3( \pm 0.01) \mathrm{mm}$ were deformed into a round shape $(=\phi 7 \mathrm{~mm})$ and heated up about $500 \mathrm{~K}$. Vickers hardness was measured by using applied load of $1.98 \mathrm{~N}$ and loading time of $10 \mathrm{~s}$. HV values employed were averaged at least 5 points excluding the lowest and highest values. In order to investigate the shape memory and superelastic characteristics quantitatively, cyclic tensile tests were carried out at room temperature by constant strain increment of $1 \%$ per a loading-unloading cycle under the initial strain rate of $4.16 \times 10^{-4} \mathrm{~s}^{-1}$.

\section{Results and Discussion}

\subsection{Effect of Sn content on superelasticity}

Figure 1 shows results of the convenient bending tests in the Ti5Mo, Ti5Mo3Sn and Ti5Mo5Sn after the solution treatment at $1273 \mathrm{~K}$ for $1.8 \mathrm{ks}$. The incomplete shape memory 
Ti5Mo
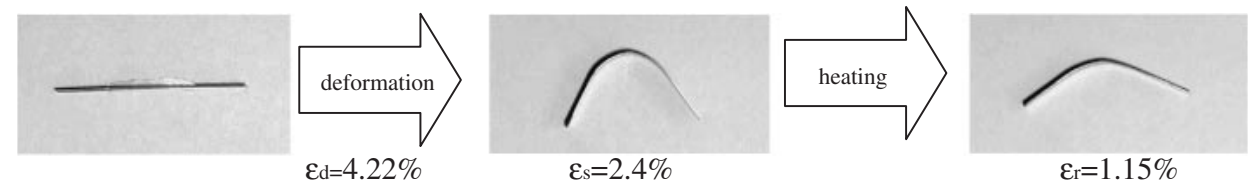

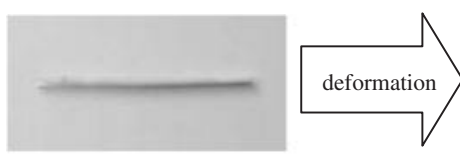

$\varepsilon \mathrm{d}=4.19 \%$

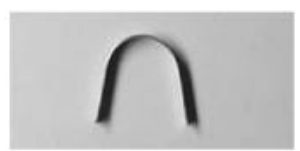

$\varepsilon_{\mathrm{s}}=2.97 \%$
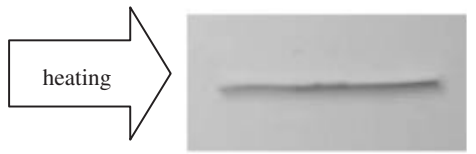

$\varepsilon_{\mathrm{r}}=0 \%$

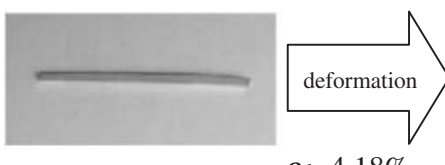

$\varepsilon_{\mathrm{d}}=4.18 \%$

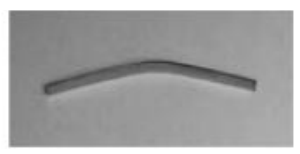

$\varepsilon_{\mathrm{s}}=0.71 \%$
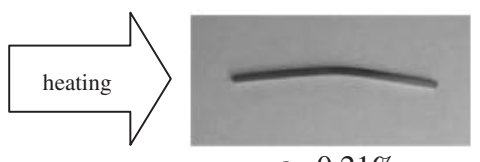

$\varepsilon_{\mathrm{r}}=0.21 \%$

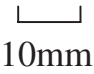

Fig. 1 Results of convenient bending and recovery test in Ti-5Mo, Ti-5Mo-3Sn and Ti-5Mo-5Sn alloys.

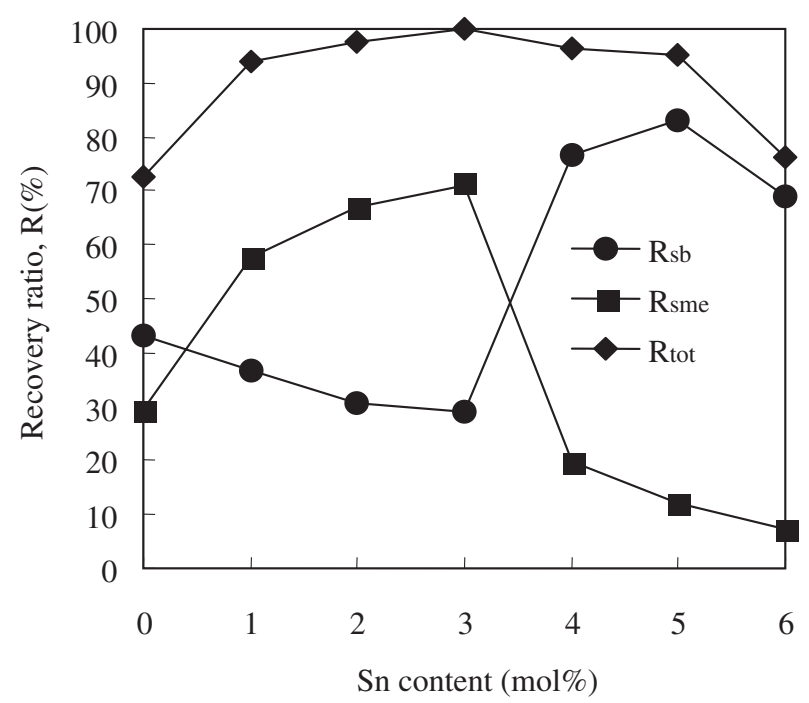

Fig. 2 Shape memory properties estimated from convenient bending test in Ti-5Mo-XSn (X = 0-6 mol\%) alloys.

effect is obtained in the Ti5Mo. On the contrary, it is clearly seen that the perfect shape memory effect is obtained in the Ti5Mo3Sn. It is agreed with a former report showing that superior shape memory effect is exhibited in the $\mathrm{Ti} 5 \mathrm{Mo}(2-$ 3)Sn. ${ }^{8)}$ Large spring back is obtained after deformation in the Ti5Mo5Sn. However, little shape memory effect is exhibited after heating.

Shape recovery properties in the $\mathrm{Ti} 5 \mathrm{Mo}(0-6) \mathrm{Sn}$ estimated from the convenient bending tests are summarized in Fig. 2. Recovery ratio $R_{\mathrm{sb}}$ with spring back after deformation and $R_{\text {sme }}$ with shape memory effect after heating are defined as follows, respectively;

$$
\begin{aligned}
& R_{\mathrm{sb}}=\left(\varepsilon_{\mathrm{d}}-\varepsilon_{\mathrm{s}}\right) / \varepsilon_{\mathrm{d}} \times 100(\%) \\
& R_{\mathrm{sme}}=\left(\varepsilon_{\mathrm{s}}-\varepsilon_{\mathrm{r}}\right) / \varepsilon_{\mathrm{d}} \times 100(\%)
\end{aligned}
$$

In addition to $R_{\mathrm{sb}}$ and $R_{\mathrm{sme}}$, the recovery ratio is defined as follows;

$$
R_{\mathrm{tot}}=R_{\mathrm{sb}}+R_{\mathrm{sme}}(\%)
$$

where $\varepsilon_{\mathrm{s}}$ : surface strain after bending deformation, $\varepsilon_{\mathrm{r}}$ : residual surface strain after heating and $\varepsilon_{\mathrm{d}}$ : applied surface strain with bending deformation, respectively.

The $R_{\text {sme }}$ increases with increasing $\mathrm{Sn}$ content up to $3 \mathrm{~mol} \%$ and then decreases with increasing $\mathrm{Sn}$ content up to $6 \mathrm{~mol} \%$. On the other hand, the $R_{\mathrm{sb}}$ decreases slightly with increasing Sn content up to $3 \mathrm{~mol} \%$ and increases drastically with increasing Sn content up to $5 \mathrm{~mol} \%$ and then decreases in $6 \mathrm{~mol} \% \mathrm{Sn}$. It has been reported that martensitic transformation temperature decreases with increasing Sn content in the $\mathrm{Ti}-\mathrm{Mo}-\mathrm{Sn}^{8)}$ and $\mathrm{Ti}-\mathrm{Nb}-\mathrm{Sn}$ alloys. ${ }^{4)}$ These facts explain the result of the convenient bending test as follows. Shape memory effect and superelastic behavior was due to the rearrangement of martensite variants and stress induced martensitic transformation during deformation followed by the reverse transformation upon heating or unloading. The stress induced martensites were remained upon unloading, and then the shape is recovered with the $\alpha^{\prime \prime} \rightarrow \beta$ reverse martensitic transformation by heating in the Ti5Mo(0-3)Sn. The $R_{\mathrm{sb}}$ increases drastically in the Ti5Mo(4-5)Sn. The reverse transformation probably happens because the start temperature for reverse transformation $A_{\mathrm{s}}$ is lower than the room temperature in addition to the recovery of elastic strain upon unloading. All $R_{\text {tot }}$ shows a high recovery ratio more than $95 \%$ in the Ti5Mo(1-5)Sn, while the $R_{\text {tot }}$ in the Ti5Mo is $73 \%$. It is clear from the bending tests, the addition of Sn up to $5 \mathrm{~mol} \%$ is effective to improve the shape memory effect and superelastic behavior in Ti5Mo. Both $R_{\mathrm{sb}}$ and $R_{\text {sme }}$ decrease in the Ti5Mo6Sn, as a result $R_{\text {tot }}$ is decreased rapidly. Permanent plastic deformation occurs because the finish temperature for reverse transformation $A_{\mathrm{f}}$ decreases far from the room temperature in the Ti5Mo6Sn. It is generally 

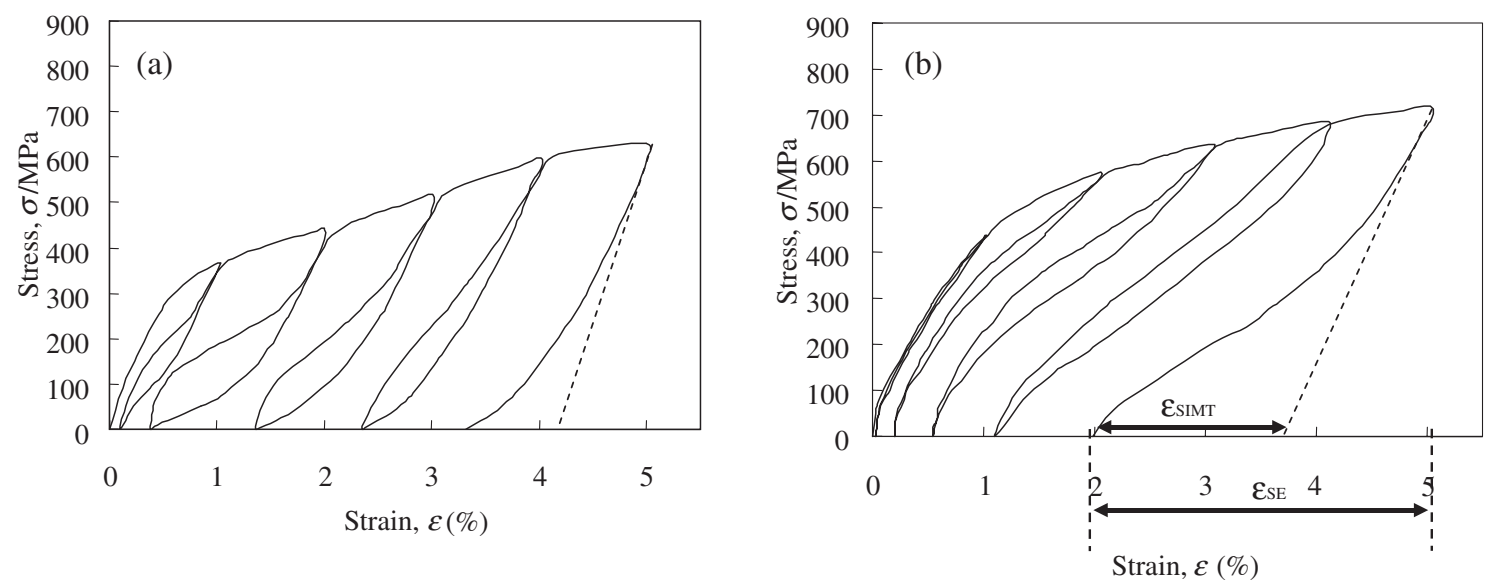

Fig. 3 Stress-strain curves from cyclic tensile test in (a) Ti-5Mo-4Sn and (b) Ti-5Mo-5Sn alloys at room temperature.
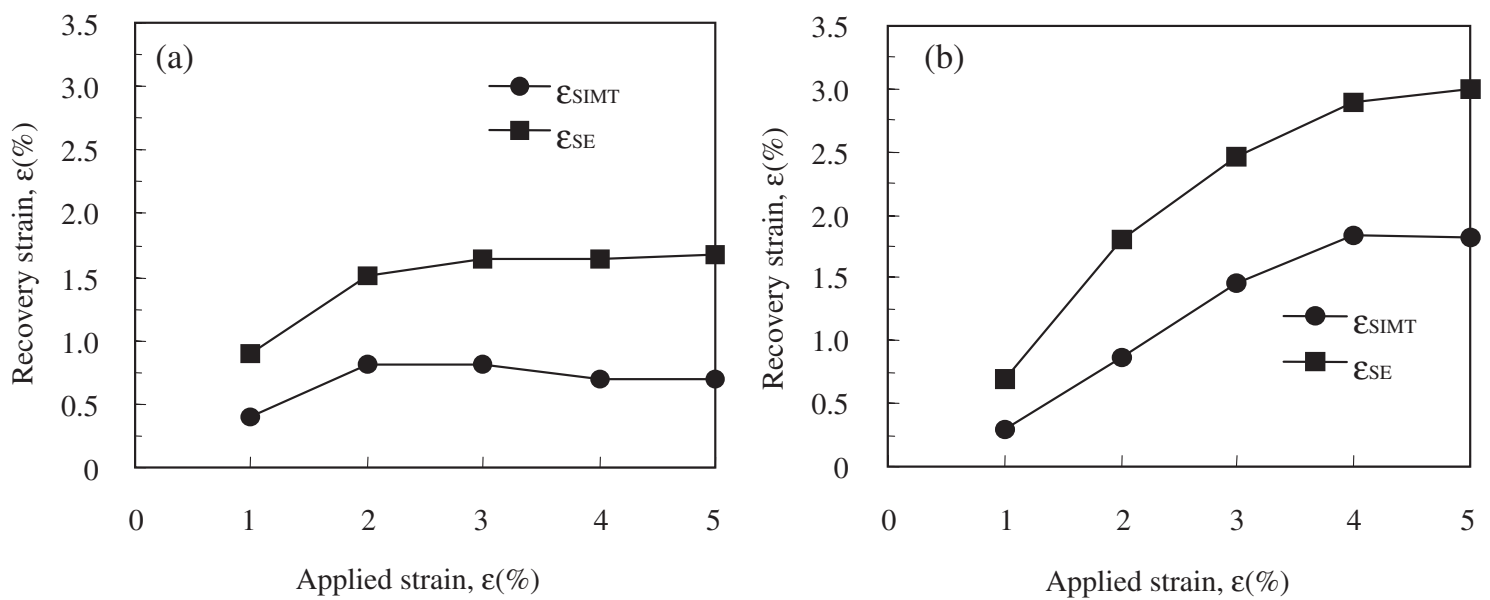

Fig. 4 Effect of applied strain on superelasticity of (a) Ti-5Mo-4Sn and (b) Ti-5Mo-5Sn alloys.

accepted that superelasticity appears most significantly at a temperature about $20-30 \mathrm{~K}$ higher than $A_{\mathrm{f}}$. Considering the results of convenient bending test and the decrease of transformation temperature with increasing Sn content, the suitable alloy composition to obtain a large superelastic strain at room temperature are the Ti5Mo4Sn or Ti5Mo5Sn. Therefore, the Ti5Mo4Sn and Ti5Mo5Sn were investigated hereafter.

Figure 3 shows the stress-strain curves obtained by loading and unloading cyclic tensile test at room temperature in the $\mathrm{Ti} 5 \mathrm{Mo}(4-5) \mathrm{Sn}$. In the stress-strain curves of both alloys, the incomplete superelastic behavior was observed. Recovery strain with stress induced martensitic reverse transformation is denoted by $\varepsilon_{\text {SIMT }}$, total recovery strain with superelasticity is also denoted $\varepsilon_{\mathrm{SE}}$ as shown in Fig. 3(b). The $\varepsilon_{\text {SIMT }}$ and $\varepsilon_{\text {SE }}$ are plotted in Fig. 4 as a function of applied strain. The $\varepsilon_{\text {SIMT }}$ increases with increasing applied strain up to $2 \%$ and then decreases in the Ti5Mo4Sn as shown in Fig. 4(a). The maximum superelastic strain $\left(=\varepsilon_{\mathrm{SE}}\right)$ is $1.7 \%$, where the applied strain is $5 \%$. The $\varepsilon_{\text {SIMT }}$ gradually increases with increasing applied strain up to $4 \%$ in the Ti5Mo5Sn as shown in Fig. 4(b). Finally, the maximum superelastic strain $\left(=\varepsilon_{\mathrm{SE}}\right)$ is $3 \%$, where the applied strain is $5 \%$. From the above results, the optimum alloy composition to obtain a large superelastic strain at room temperature is determined to be the Ti5Mo5Sn. This alloy is also expected to the improvement of the superelasticity by aging.

\subsection{Effect of aging conditions on superelasticity}

Acceleration of the $\alpha^{\prime \prime}$ martensitic transformation by a short time aging at intermediate temperature, where $\omega$ phase never precipitated and the $\alpha$ laths were ready nucleated, was observed in a commercial $\beta$ phase alloy $\mathrm{Ti}-10 \mathrm{~V}-2 \mathrm{Fe}-3 \mathrm{Al}$ (by mass\%). ${ }^{13,14)}$ Superelasticity was improved by short time aging at $873 \mathrm{~K}$ after solution treatment in the $\beta$-type Ti$16 \mathrm{Nb}-4.9 \mathrm{Sn}$ alloy. ${ }^{4)}$ These phenomena is probably common in $\beta$-Ti alloys. Thus, the Vickers hardness test and convenient bending test are performed in the Ti5Mo5Sn aged at 623$873 \mathrm{~K}$. Figure 5 shows the Vickers hardness changes with the aging conditions. The HV value of specimens aged at 623 , $673 \mathrm{~K}$ is higher than that of solution treated alloy because of the precipitation of thermal $\omega$ phase. The HV value increases slightly with an increasing aging time up to $60 \mathrm{~s}$ in the specimen aged at 773 and $873 \mathrm{~K}$. It is supposed that a small amount of thermal $\omega$ phase which forms during heating to the aging temperature is not able to be resolved within $60 \mathrm{~s}$. And then, the hardness decreased to the nearly same value of solution treated alloy. This well corresponds to the result in the $\mathrm{Ti}-10 \mathrm{~V}-2 \mathrm{Fe}-3 \mathrm{Al}$ alloy. Therefore, the improvement of superelasticity by the aging in 773 and $873 \mathrm{~K}$ is expected. 


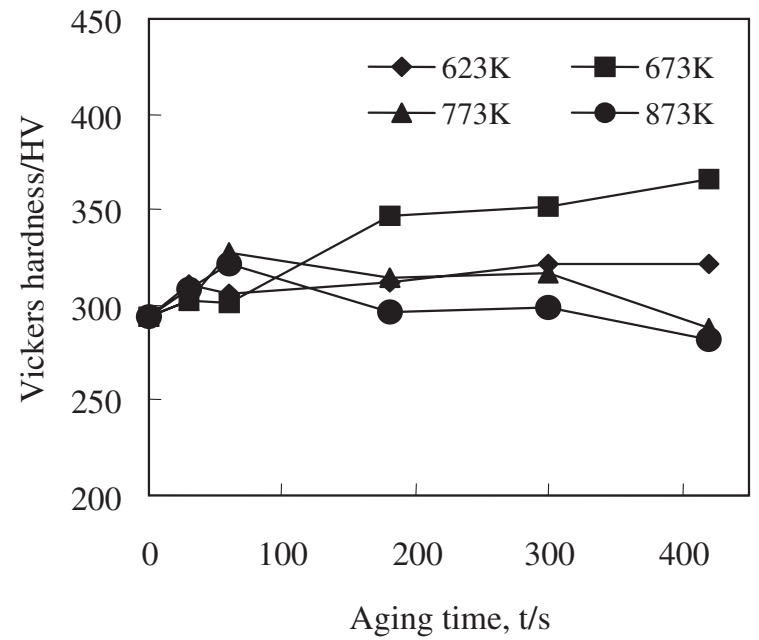

Fig. 5 Changes in Vickers hardness with aging conditions in $\mathrm{Ti}-5 \mathrm{Mo}-5 \mathrm{Sn}$ alloys.

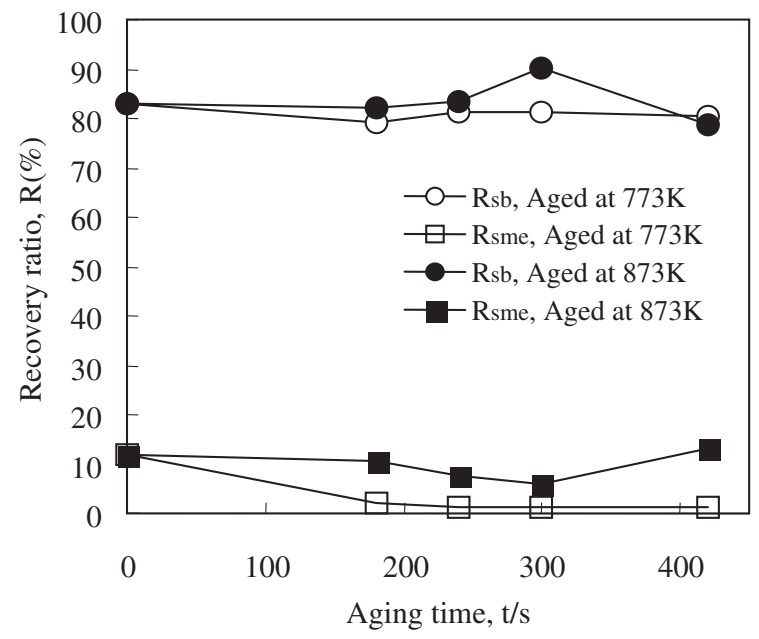

Fig. 6 Effect of aging time on shape recovery properties estimated from convenient bending test of $\mathrm{Ti}-5 \mathrm{Mo}-5 \mathrm{Sn}$ alloys.

The effect of short time aging at 773 and $873 \mathrm{~K}$ on superelasticity is investigated by the convenient bending test as shown in Fig. 6. There is little change in $R_{\mathrm{sb}}$ of the specimens aged at $773 \mathrm{~K}$. On the other hand, the $R_{\mathrm{sb}}$ gradually increases with an increasing aging time up to $300 \mathrm{~s}$ and then decreases in the specimen aged at $873 \mathrm{~K}$. Thus, optimum aging condition to obtain a large superelastic recovery strain is at $873 \mathrm{~K}$ for $300 \mathrm{~s}$ in the Ti5Mo5Sn.

The quantitative measurement of superelastic strain is performed in Ti5Mo5Sn aged at $873 \mathrm{~K}$ for $300 \mathrm{~s}$ by loading and unloading cyclic tensile test as shown in Fig. 7. It is understood that the superelastic behavior is clearly appeared upon unloading in comparison to the specimen solution treated as shown in Fig. 3(b). The maximum superelastic strain is $3.5 \%$, where the applied strain is $5 \%$. In order to clarify the effect of aging on superelasticity, the $\varepsilon_{\text {SIMT }}$ and $\varepsilon_{\mathrm{SE}}$ are plotted in Fig. 8 as a function of applied strain. The $\varepsilon_{\text {SIMT }}$ gradually increases with increasing applied strain up to $4 \%$ and decreases in the solution treated specimen. On the other hand, $\varepsilon_{\text {SIMT }}$ consistently increases with increasing applied

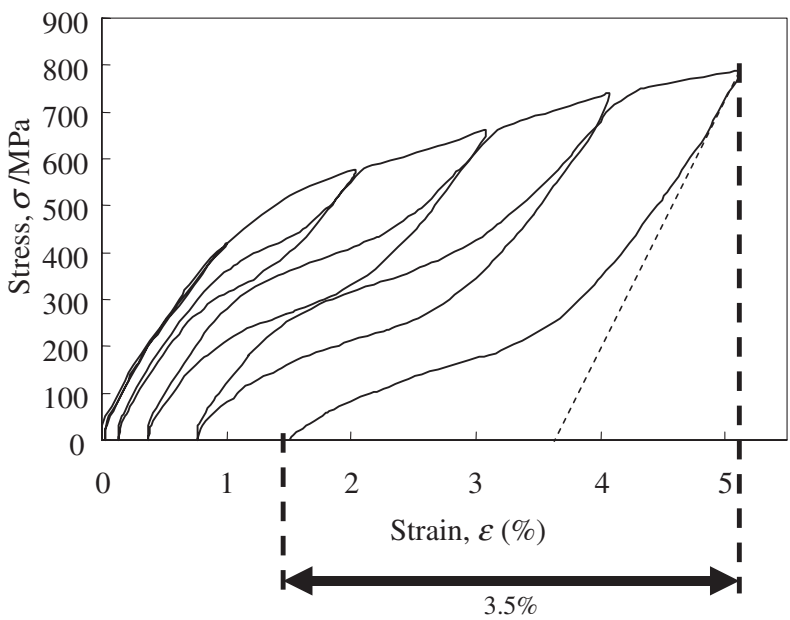

Fig. 7 Stress-strain curves obtained from cyclic tensile test at room temperature in $\mathrm{Ti}-5 \mathrm{Mo}-5 \mathrm{Sn}$ alloy aged at $873 \mathrm{~K}$ for $300 \mathrm{~s}$ after solution treatment.

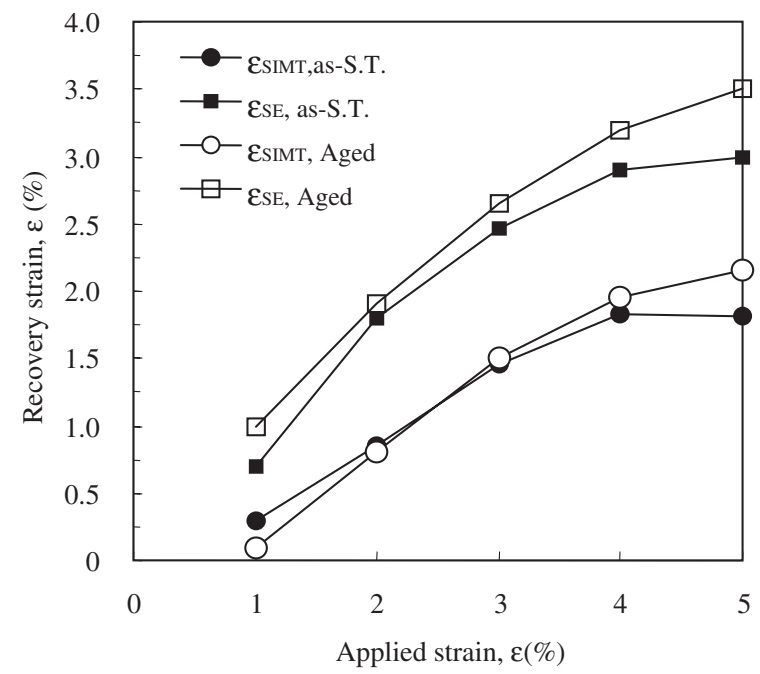

Fig. 8 Effect of applied strain on superelasticity of Ti-5Mo-5Sn alloy solution treated and aged at $873 \mathrm{~K}$ for $300 \mathrm{~s}$ after solution treatment.

strain in the aged specimen. It is clear in Fig. 8 that increase in $\varepsilon_{\text {SIMT }}$ contribute to improve total recovery strain $\varepsilon_{\mathrm{SE}}$ in the aged specimen. The improvement of superelasticity by aging is attributable to the increment of recovery strain associated with the reverse transformation of stress induced martensite. The relationship between microstructure and improvement of superelasticity by aging should be investigated in detail. This is now under study and will be reported in due course.

Since the stability of superelasticity is very important for biomedical applications, the cyclic tensile test is performed in the Ti5Mo5Sn alloy aged at $873 \mathrm{~K}$ for 300 s. Figure 9 shows the stress-strain curves during loading and unloading cyclic tensile tests in the Ti5Mo5Sn aged at $873 \mathrm{~K}$ for $300 \mathrm{~s}$. It is noted that the stable superelastic curves with recovery strain of $3 \%$ were obtained after the 5 th cycles. The recovery strain of $3 \%$ is consistently obtained up to the 15 th or more. It is concluded that the newly developed Ti-Mo-Sn alloys are promising as a substitute for Ti-Ni alloys in the biomedical field. 

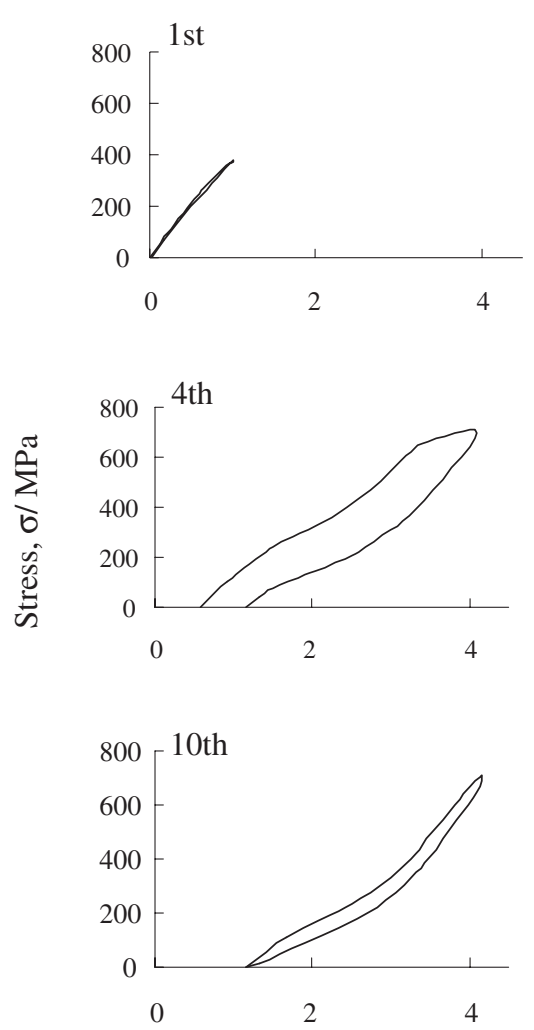

2nd

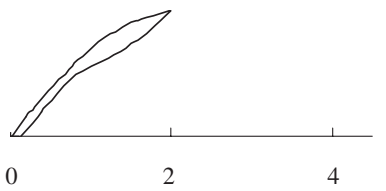

5th

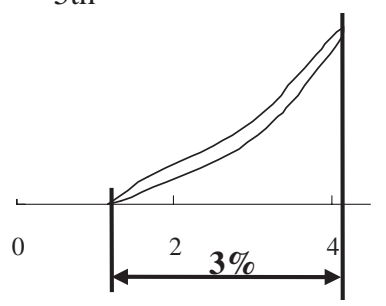

12 th

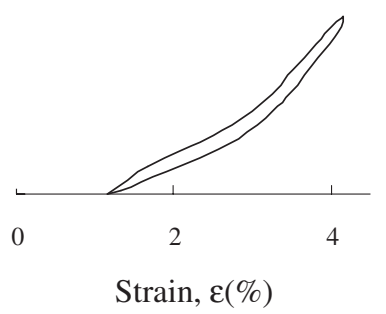

3rd

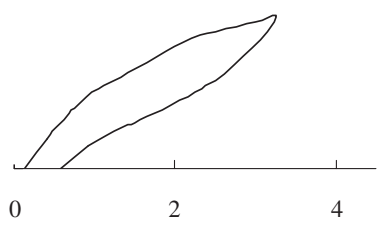

8th

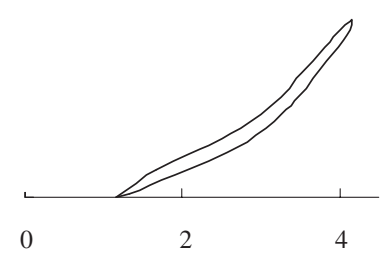

15 th

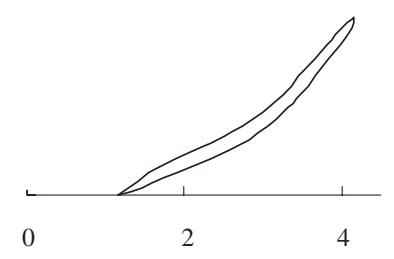

Fig. 9 Stress-strain curves of Ti-5Mo-5Sn alloy aged at $873 \mathrm{~K}$ for $300 \mathrm{~s}$ after solution treatment, where loading and unloading are repeated 15 times.

\section{Conclusions}

In order to develop biomedical shape memory and superelastic alloy, the effects of $\mathrm{Sn}$ content and aging conditions on superelasticity in biomedical Ti-Mo-Sn alloys were investigated. The obtained results are as follows;

(1) The martensitic transformation temperature decreases with increasing Sn content. The addition of Sn to the Ti-Mo is effective to improve shape memory effect and superelastic behavior.

(2) The superelasticity with a recovery strain of $3 \%$ is obtained in $\mathrm{Ti}-5 \mathrm{Mo}-5 \mathrm{Sn}$ alloy solution-treated at $1273 \mathrm{~K}$ for $1.8 \mathrm{ks}$.

(3) The short time aging is effective to improve the superelasticity. The maximum superelastic strain of $3.5 \%$ and the stable superelastic strain of $3 \%$ are obtained in Ti-5Mo-5Sn alloy aged at $873 \mathrm{~K}$ for $300 \mathrm{~s}$ after solution treatment.

(4) The recovery strain with stress induced martensitic transformation $\left(\varepsilon_{\text {SIMT }}\right)$ increases with increasing applied strain in Ti-5Mo-5Sn alloy. The amount of an increase $\varepsilon_{\text {SIMT }}$ in the aged alloy is large than that in the solution treated alloy, accordingly superelastic strain $\varepsilon_{\mathrm{SE}}$ has increased in the aged alloy.

\section{REFERENCES}

1) C. Baker: Metal Sci. J. 5 (1971) 92-100.

2) H. Hosoda, N. Hosoda and S. Miyazaki: Trans. MRSJ 26 (2001) 243246.

3) H. Hosoda, Y. Ohomatsu and S. Miyazaki: Trans. MRSJ 26 (2001) 243-235.

4) E. Takahashi, T. Sakurai, S. Watanabe, N. Masahashi and S. Hanada: Mater. Trans., JIM 43 (2002) 2978-2983.

5) Y. Fukui, T. Inamura, H. Hosoda, K. Wakashima and S. Miyazaki: Mater. Trans., JIM 45 (2004) 1077-1082.

6) H. Y. Kim, Y. Ohomatsu, J. I. Kim, H. Hosoda and S. Miyazaki: Mater. Trans. 45 (2004) 1090-1095.

7) H. Y. Kim, S. Hashimoto, J. I. Kim, H. Hosoda and S. Miyazaki: Mater. Trans. 45 (2004) 2443-2448.

8) T. Maeshima and M. Nishida: Mater. Trans. 45 (2004) 1096-1100.

9) T. Maeshima and M. Nishida: Mater. Trans. 45 (2004) 1101-1105.

10) T. Maeshima, K. Yamauchi, H. Uchiyama and M. Nishida: Trans. MRSJ 29 (2004) 3009-3012.

11) T. Maeshima, S. Ushimaru, K. Yamauchi and M. Nishida: J. Jpn. Inst. Met. 69 (2005) 654-658.

12) D. Kuroda, M. Niinomi, M. Morinaga, Y. Kato and T. Yashiro: Mater. Sci. Eng. A 243 (1998) 244-249.

13) Y. Ohomori, H. Natui, K. Nakai and H. Ohotsubo: Mater. Trans., JIM 39 (1998) 40-48.

14) Y. Ohomori, T. Ogo, K. Nakai and S. Kobayashi: Mater. Sci. Eng. A 312 (2001) 182-188. 